\title{
Transición del terrorismo al bioterrorismo como una amenaza para la supervivencia humana: reflexión bioética en el marco del bioderecho y la seguridad nacional*
}

\author{
[Artículos]
}

\author{
Javier Hernando Conde Mesa** \\ Amparo de Jesús Zárate Cuello*** \\ Floro Hermes Gómez-Pined $a^{* * * *}$
}

Fecha de recepción: 4 de marzo de 2021

Fecha de aprobación: 18 de mayo de 2021

\begin{abstract}
* Este escrito es producto del proyecto de investigación: "El bioterrorismo y su impacto en el Estado colombiano partiendo de una mirada desde la bioética, la biopolítica y el derecho", gestionado en el marco del programa del Doctorado en Bioética de la Universidad Militar Nueva Granada (Bogotá, Colombia)

** Administrador Aeronáutico de la Escuela Militar de Aviación Marco Fidel Suárez (EMAVI), especialista en Seguridad y Defensa Nacionales de la Escuela Superior de Guerra, magíster en Educación de la Universidad Militar Nueva Granada (Bogotá, Colombia) y, actualmente, estudiante del Doctorado en Bioética, Universidad Militar Nueva Granada (Bogotá, Colombia). Miembro del grupo de investigación Masa Crítica de la Escuela Superior de Guerra de Colombia "General Rafael Reyes Prieto". Correo electrónico: javier.conde@unimilitar.edu.co. ORCID: https://orcid.org/0000-0001-7152-9399

*** Abogada de la Universidad Libre de Colombia. Doctora en Derecho, Departamento de Filosofía del Derecho, en la línea Persona, Sociedad y Derecho: Legitimidad y Legalidad de la Universidad Complutense de Madrid. Investigadora en filosofía del derecho, Universidad Nacional de España (UNED), Madrid. Experta en derecho de familia, derecho administrativo, promoción en salud y desarrollo humano. Actualmente es docente investigadora en la Facultad de Educación y Humanidades y en el Doctorado de Bioética de la Universidad Militar Nueva Granada (Bogotá, Colombia). Docente titular-Facultad Ciencias Básicas. Universidad Colegio Mayor de Cundinamarca. Miembro Comité Ética en Investigación Clínica (CIEC). Docente invitada de universidades europeas y conferencista nacional e internacional. Correo electrónico: amparo.zarate@unimilitar.edu.co. ORCID: https://orcid.org/0000-0003-4978-6377 **** Médico de la Universidad Libre, especialista en Bioética de la Universidad del Valle y doctor en Estudios Políticos de la Universidad Externado de Colombia. Profesor de jornada completa del Área Social, Comunitaria y Humanística de la Facultad de Ciencias de la Salud de la Seccional Cali de la Universidad Libre e integrante del grupo de investigación Estudios en Bioética, Ecología Humana y Ecología Política. Con(S)ciencia. Correo electrónico: floro.gomez@unilibre.edu.co. ORCID: https://orcid.org/0000-0002-5465-8823
\end{abstract}

Via Inveniendi Et Iudicandi

e-ISSN: 1909-0528 | DOI: https://doi.org/10.15332/19090528

Vol. 16 N.o 2 | julio-diciembre del 2021 
Citar como

Conde-Mesa, J. H., Zárate-Cuello, A. de J. y Gómez-Pineda, F. H. (2021). Transición del terrorismo al bioterrorismo como una amenaza para la supervivencia humana: reflexión bioética en el marco del bioderecho y la seguridad nacional. Via Inveniendi Et Iudicandi, 16(2). https://doi.org/10.15332/19090528.6779

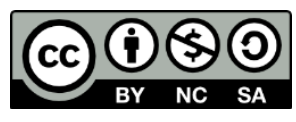

\section{Resumen}

Hacer una reflexión bioética en el marco del bioderecho y la seguridad nacional es una manera de entender la transición del terrorismo al bioterrorismo como una amenaza para la supervivencia humana, de los vivientes y del ecosistema en todas sus manifestaciones. Esta reflexión requiere entrelazar las ciencias de la vida con las humanidades, con el propósito de coadyuvar a la construcción epistemológica de esta amenaza, cuya noción en la literatura científica adolece de una definición de carácter jurídico, frente a la multiplicación de los riesgos biológicos que afectan especialmente al Homo sapiens sapiens, en torno a la seguridad nacional, seguridad humana y seguridad ambiental. El análisis realizado presenta, de manera holística, el impacto de la amenaza bioterrorista en el ámbito global, así como para el Estado colombiano y la necesidad urgente de regulación del uso de armas y agentes biológicos en Colombia.

Palabras clave: terrorismo, bioterrorismo, bioética, bioderecho, supervivencia humana, seguridad nacional, seguridad humana.

\section{Transition from terrorism to bioterrorism as a threat to human survival: bioethical reflection in the framework of biolaw and national security}

\section{Abstract}

A bioethical reflection within the framework of biolaw and national security is a way to understand the transition from terrorism to

Via Inveniendi Et Iudicandi

e-ISSN: 1909-0528 | DOI: https://doi.org/10.15332/19090528

Vol. 16 N.० 2 | julio-diciembre del 2021 
bioterrorism as a threat to human survival, survival of the living and the ecosystem in all its manifestations. This reflection requires intertwining the life sciences with the humanities, in order to contribute to the epistemological construction of this threat, whose notion in the scientific literature lacks a legal definition, in the face of the multiplication of biological risks that especially affect Homo sapiens sapiens, around national security, human security and environmental security. The analysis presents, in a holistic manner, the impact of the bioterrorist threat at the global level, as well as for the Colombian State and the urgent need to regulate the use of biological weapons and agents in Colombia.

Keywords: Terrorism, bioterrorism, bioethics, biolaw, human survival, national security, human security.

\section{Introducción}

Este artículo examina el paso del terrorismo al bioterrorismo, realiza una reflexión bioética dentro del marco del bioderecho y la seguridad nacional, y señala los riesgos que representa el terrorismo biológico para la supervivencia humana.

Para avanzar en la narrativa frente a este flagelo, al inicio, el abordaje se considerará, partiendo del concepto de terrorismo, desde la mirada de varios autores que confluyen desde el ámbito de la filosofía, la historia, la ciencia política, la psicología, las ciencias sociales y la seguridad pública; cuya epistemología es importante examinar cronológicamente, con el propósito de coadyuvar a la contextualización del bioterrorismo que se da significativamente a nivel global, así como su impacto en el Estado colombiano.

Los apartados para el desarrollo del presente documento de análisis harán alusión a la conceptualización del terrorismo y su transición al bioterrorismo; su condición de amenaza para la supervivencia humana; 
las reflexiones que desde la bioética y el bioderecho se realizan de cara al terrorismo y al bioterrorismo, y, finalmente, el impacto generado por el bioterrorismo en la seguridad en el ámbito global, así como su impacto en el Estado colombiano. De manera complementaria, y como resultado del proceso de análisis e investigación realizado, se presentarán las conclusiones por parte de los autores.

\section{Conceptualización del terrorismo}

Indagar ¿qué es terrorismo?, es preguntar por una de esas cuestiones que se sabe no tienen, ni van a tener, una contestación definitiva, porque pertenecen a preguntas-límites, en el mismo sentido que la filosofía de Karl Jaspers ${ }^{1}$; pero, en nuestro caso, en los ámbitos de la teoría y práctica de la política, del derecho y de los fenómenos colectivos que nacen de la práctica social del hombre.

\section{Noción de terrorismo}

Torres Vásquez (2009) señala que el terrorismo es "uno de los inconvenientes más serios de la sociedad contemporánea [...], específicamente por la inseguridad colectiva que genera su accionar" (p. 140); pero, ¿qué es terrorismo?

Al preguntar ¿qué es terrorismo?, surge la cuestión a propósito de la proveniencia del término. La respuesta es que este vocablo es de origen francés, "aparece [...] en 1793 para designar el régimen de terror político durante los años revolucionarios impuesto por Robespierre" (Al Kaabi, 2017, p. 5). Este consistió "en la difusión en todas las provincias [francesas] del terror de 1793 nacido en París. Fue un sistema establecido

\footnotetext{
1 Jaspers en su filosofía une la muerte (que es una situación límite) con la angustia, en especial. Esta asume dos formas, por una parte, la angustia consciente y, por la otra, la angustia evasiva y desesperada. Esta última surge del espanto, es un miedo.
}

Via Inveniendi Et Iudicandi

e-ISSN: 1909-0528 | DOI: https://doi.org/10.15332/19090528

Vol. 16 N.o 2 | julio-diciembre del 2021 
por los que estaban en el poder para paralizar con un miedo increíble, en sentido estricto, cualquier inclinación contrarrevolucionaria" (Gayraud y Senat, 2002, p. 32); es decir, corresponde a la situación excepcional del uso del terror como estrategia estatal en condiciones de subversión social. Sin embargo, por una parte, Laqueur (2003) señala que después del 9 de Thermidor perdió la connotación de estrategia estatal y pasó a significar un abuso con implicaciones delictivas como consecuencia de las crueldades padecidas durante dicho régimen de terror (pp. 36-37). Por la otra, al preguntar por el origen del fenómeno, como lo advierte el propio Juma Al Kaabi (2017), citando a Mario Bettati, es sorprendente que, aunque "la palabra solo aparece a finales del siglo XVIII, el fenómeno, en cuanto tal, ha existido y acompañado 'todos los momentos de la historia política y social' de los pueblos" (p. 5).

Más allá de estas consideraciones sobre la expresión propias de la teoría y práctica de la política, Ariel Merari (2002) advierte que

La palabra terrorismo se ha convertido en un término pura y simplemente desacreditador en lugar de un término que describe un tipo actividad específica. En general, la gente lo usa para expresar desaprobación de una variedad de fenómenos que les desagradan, sin molestarse en definir con precisión lo que constituye un comportamiento terrorista. (p. 73)

Esta precisión es difícil de alcanzar de acuerdo con el jurista Stephano Manacorda (2013), quien señala que

los que son terroristas para un Estado aparecerán ante otros Estados como luchadores por la libertad que deben ser protegidos. Buscar un acuerdo entre estas diferentes visiones para llegar a un punto de vista que, en lo menos tendencioso, quiera ser universalista, representa una tarea particularmente ardua. (p. 191)

Via Inveniendi Et Iudicandi e-ISSN: 1909-0528 | DOI: https://doi.org/10.15332/19090528 
Es decir, que la naturaleza de "qué es terrorismo" depende de la perspectiva, los intereses y posiciones políticas.

Esta situación, marcadamente ideológica, de puntos de vista, intereses y posiciones disímiles, se refleja en múltiples intentos de definición desde distintos campos del saber. A manera de ejemplo, los siguientes cuatro intentos ilustran la definición desde diferentes miradas:

1. Para el filósofo Raymond Aron (1962), “una acción violenta es denominada terrorista cuando sus efectos psicológicos son desproporcionados frente sus resultados físicos" (p. 176).

2. Para el historiador Walter Laqueur (1979), es "el uso de una violencia enmascarada por un grupo con fines políticos y dirigida contra un gobierno o un grupo étnico, de clase o de partido" (p. 89).

3. Para la politóloga, Isabelle Sommier (2000), es un acto que "ignora las leyes y convenciones de la guerra, ataca a civiles, es siempre indiscriminado y arbitrario en virtud de la separación que opera entre víctima y objetivo" (p. 78).

4. Para los psicólogos sociales, Arie W. Kruglanski y Shira Fishman (2009), se concibe el "terrorismo como el uso simbólico de la violencia por parte de actores no estatales con efectos sociales y políticos (por lo tanto, no puramente criminales) objetivos destinados a intimidar, asustar o coaccionar a una audiencia más amplia que los objetivos directos (instrumentales) del ataque" (p. 3).

Estas cuatro miradas académicas - entre las muchas existentes- sobre "qué es terrorismo", que pretenden unos significados propios más allá de las consideraciones ideológicas, muestran la dificultad (casi la imposibilidad) que existe para conceptualizar el término, aunque señalan unos rasgos que nos permiten afirmar que una acción es terrorista cuando hace uso simbólico indiscriminado arbitrario de la violencia, procurando efectos psicológicos desproporcionados con el propósito de intimidar, 
asustar o coaccionar a un gobierno o sectores no estatales, tales como un grupo étnico, de clase o de partido.

\section{Clases de terrorismo}

Existen muchas clasificaciones de terrorismo, siendo las más comúnmente repetidas las que tienen relación con su radio de acción, sus objetivos y finalidades, y sus medios (Huertas, López y Jerez Avilán, 2019). Con respecto a la primera de ellas, Rodríguez-Morales (2012) señala que se lo puede catalogar local o regional, o global o internacional. El primero "Es un terrorismo concentrado en un lugar específico [...], de tal forma que sus acciones van dirigidas sólo a la población de un espacio geográfico concreto". El segundo, es "el terrorismo del que actualmente el mundo es víctima, es resultado de la convergencia en Pakistán en 1989, de un numeroso grupo de combatientes que participó de la expulsión de los soviéticos de Afganistán [quienes] recibieron entrenamiento en tácticas de guerra, manejo y conocimiento de armas" (pp. 79-8, 81).

En lo atinente a la segunda clasificación, los objetivos y finalidades, Gilberto Santa Rita Tamés (2012) lo cataloga así:

a) Terrorismo revolucionario: se fundamentan en extremismos ideológicos y clamor popular. Los ideales que les sirven de fundamento suelen ser de naturaleza utópica y con pocas posibilidades de materializarse [...].

b) Terrorismo represivo: Dentro de esta clasificación tanto el Estado como los grupos subversivos pueden ejercer la violencia de forma indistinta, pero cuando emana del Estado en contra de la población la agresividad estatal puede tener como fundamento la falta de control o gobernabilidad sobre un sector rebelde de la población [...].

c) Terrorismo religioso: Considerado de mayor peligrosidad debido a que para el o los atacantes, su actuar se encuentra absolutamente

Via Inveniendi Et Iudicandi

e-ISSN: 1909-0528 | DOI: https://doi.org/10.15332/19090528

Vol. 16 N.० 2 | julio-diciembre del 2021 
legitimado [por la existencia de un código sacrificio/recompensa, que representa un fortísimo estimulante para el terrorista]. El fundamento religioso al ser dogmático priva de cualquier tipo de inhibiciones al sujeto que ha de ejecutar el atentado terrorista. (pp. 38-39)

Finalmente, en cuanto tiene que ver los medios, González y Fernández (2008) expresan que estos deben ser "capaces de causar grave daño a la vida" (p. 49); lo cual ha de entenderse que junto a las armas tradicionales deben contemplarse las armas químicas, las radioactivas, las nucleares o las biológicas, por tener esa capacidad.

Por esta razón, como lo considera Ramírez-Gil (2014), el uso de agentes biológicos como instrumento de terror, "se puede considerar una expresión particular del terrorismo" (p. 66), la cual "se trata de una de las manifestaciones del denominado 'terrorismo asimétrico" (MatamorosMartínez, 2004, p. 24), que es "una táctica para compensar las ventajas de los fuertes" que consiste en atacar a "los civiles más fuertes del adversario" (Culp, 2019, p. 19).

\section{Conceptualización del bioterrorismo}

En cuanto expresión particular del terrorismo, el bioterrorismo es -según Gema Sánchez Medero (2018) - "una de la (sic) más terribles amenazas" (p. 183), ¿̇por qué considerarlo como tal? Por las características mortíferas que deben poseer los agentes biológicos para ser utilizados como armas, los cuales los señalan con precisión: Franco-Paredes y Rodríguez (2004). Tales características son:

(1) que causen elevada morbilidad y mortalidad, (2) que se transmitan de persona a persona, (3) que tengan una baja dosis infecciosa, (4) que sean altamente infectantes al ser diseminados como aerosol y, por tanto, tengan la capacidad para causar grandes brotes, (5) que no exista una vacuna contra el agente o que ésta sea de disponibilidad limitada, (6) que

Via Inveniendi Et Iudicandi

e-ISSN: 1909-0528 | DOI: https://doi.org/10.15332/19090528

Vol. 16 N.o 2 | julio-diciembre del 2021 
exista el potencial para ser producido a gran escala, y (7) que se trate de un agente estable en el medio ambiente. (p. 31)

¿Por qué se procuran agentes infecciosos con estas características biológicas? El farmacólogo Lorène Clauzon (2009) nos explica que, se busca que los agentes biológicos empleados como armas posean estas características infecciosas, porque

[el objetivo del bioterrorismo es causar] patologías incapacitantes o incluso fatales e [inducir] un sentimiento de terror [al que] las poblaciones civiles son más vulnerables que el personal militar, porque reúnen a personas de todas las edades, de todos los estados de salud, no entrenadas ni protegidas, para hacer frente a este tipo de ataque. (p. 1) ${ }^{2}$

\section{Noción de bioterrorismo}

Como lo accesorio sigue la suerte de lo principal, siendo el bioterrorismo una forma del terrorismo, no menos compleja ha sido la tentativa de una definición; al respecto, los Centers for Disease Control and Prevention (CDC), que son una agencia del United States Department of Health and Human Services, definen la acción mas no su naturaleza, así: "un ataque biológico, o bioterrorismo, es la liberación intencional de virus, bacterias $\mathrm{u}$ otros gérmenes que pueden infectar o matar a las personas, los ganados o los cultivos" (CDC, 2014, p. 10); es decir que, de acuerdo con esta definición, puede amenazar la vida toda, situación que requiere del análisis bioético3.

Sin embargo, como en el terrorismo, se han intentado establecer unas definiciones; señalamos algunos ejemplos:

\footnotetext{
${ }^{2}$ El texto fue tomado, traducido y ajustado al texto del artículo a partir de Lorène Clauzon (2009).

${ }^{3}$ La bioética es una "manera tecno científica de deliberar sobre la vida toda, a partir de la cual se ha de valorar sus riesgos [para] entender qué decidir de forma responsable, una cuestión que es, sin duda, moral" (Gómez-Pineda, 2014, p. 135).
}

Via Inveniendi Et Iudicandi

e-ISSN: 1909-0528 | DOI: https://doi.org/10.15332/19090528

Vol. 16 N.o 2 | julio-diciembre del 2021 
1. Desde la perspectiva de la salud pública, Soberanis y Ramos (2009) consideran el bioterrorismo como un problema de la salud pública, lo definen como "el uso ilegítimo (o amenaza de uso) de microorganismos o toxinas obtenidas de organismos vivos para provocar enfermedades o muerte en seres humanos, animales o plantas con el objetivo de intimidar a gobiernos o sociedades para alcanzar objetivos ideológicos, religiosos o políticos” (p. 29).

2. Desde una mirada de la seguridad nacional, la Government Accountability Office (GAO), de los Estados Unidos de América expresa que el bioterrorismo "es la amenaza o liberación intencional de agentes biológicos (virus, bacterias o sus toxinas) con el propósito de influir en la conducta del gobierno o intimidar o coaccionar a la población civil" (GAO, 2001).

3. Desde el mundo de lo político, en el informe sobre bioterrorismo - presentado por el diputado, Pierre Lang (2003), al presidente de la Asamblea Nacional de Francia con destino a la Comisión Nacional de Defensa y Fuerzas Armadas-, se le define al terrorismo biológico en un sentido amplio como "el uso ideológico de agentes biológicos (virus, bacterias), pero también toxinas (sustancias tóxicas secretadas por organismos vivos) con el fin de infligir daño a los seres humanos, animales o plantas con fines de intimidación y terror" (p. 5).

Ahora bien, bajo este entendido, se puede calificar una acción como bioterrorista cuando hace uso ideológico, religioso o político ilegítimo (o amenaza con su uso) de agentes biológicos (virus, bacterias o sus toxinas) para infligir daño en seres humanos, animales o plantas con el propósito de influir en la conducta del gobierno o intimidar, coaccionar o producir terror en la población civil, en tal virtud, surge la cuestión: ¿qué se desprende de este intento de definición propia? 
De nuestro ensayo de definición, se desprende que al pretender afectar la vida animal (la cual comprende la humana) y la vegetal, más allá de su objetivo de influir a un gobierno o intimidar, coaccionar o producir terror en la población, se puede colegir que es un riesgo biológico que pone en peligro la supervivencia en su sentido global; es decir, es un problema de vulnerabilidad (daño potencial).

\section{La vulnerabilidad y el bioterrorismo}

Kottow (2004) - citando el Proyecto BIOMED II (Rendtorff, 2002, pp. 235-244) - señala que "el ser humano corpóreamente encarnado es visto como vulnerable en el sentido de poder ser dañado, sometido a riesgos y amenazas contra su integridad" (p. 281). "Por consiguiente - afirma Kottow (2007) -, vulnerable implica la capacidad o potencialidad de ser afectado por una acción que vulnera" (p. 8); es decir, que es un término que hace referencia a la "finitud y fragilidad" (Cavalcante, 2017, p. 312); del que Kottow (2012) concluye que "la vulnerabilidad es un rasgo antropológico que implica la libertad y la igualdad de todos los individuos" (p. 25).

En tal sentido, todo ser humano sería vulnerable ante una acción bioterrorista, en cuanto al uso de un agente patógeno como arma biológica, que ponga en peligro la supervivencia del viviente, en su sentido global. Es decir, no solo la vida humana, sino también la del ecosistema en todas sus manifestaciones está en peligro.

\section{El bioterrorismo desde la perspectiva jurídica}

No obstante, la capacidad de infligir daño que deben poseer los agentes biológicos empleados como armas, los efectos y los sentimientos que provoca el terrorismo biológico y su propósito incapacitante, incluso fatal, y a pesar de que la Asamblea General de las Naciones Unidas estableció, en

Via Inveniendi Et Iudicandi

e-ISSN: 1909-0528 | DOI: https://doi.org/10.15332/19090528

Vol. 16 N.० 2 | julio-diciembre del 2021 
diciembre 16 de 1969, que "las armas de guerra biológicas [son contrarias a las reglas del Derecho Internacional]" (A.G. NU, 1969, A/RES/69/24). El bioterrorismo "no es una noción jurídicamente definida [toda vez que no existe] una definición internacionalmente vinculante del término 'terrorismo"' (UNODC, 2018, pp. 1-3, A/RES/60/288), ni ha sido suficientemente analizada, a pesar de ser ampliamente discutida, "la vulnerabilidad de las poblaciones humanas al terrorismo químico, biológico, radiológico y nuclear" (Ponce de León-Rosales, Lazcano-Ponce, Rangel-Frausto, Sosa-Lozano y Huerta-Jiménez, 2001, p. 589).

\section{Transición del terrorismo al bioterrorismo}

El deseo de muchas organizaciones violentas de pasar del terrorismo al bioterrorismo, que muchos han denominado el atractivo por las armas biológicas, "se atribuye al acceso fácil a un amplio rango de agentes biológicos que producen enfermedad, a sus bajos costes de producción, a su indetectabilidad por los sistemas de seguridad rutinarios y a su fácil transporte" (Oromí- Durich, 2002, p. 285),

[a] que pueden llegar a ser varios cientos de veces más letales que sus equivalentes a las armas químicas e incluso las nucleares» y que se trata «de materiales (organismos vivos o sustancias patógenas) que están en la propia naturaleza y, por tanto, al alcance de grupos interesados. (PereiraHernández, 2007, p. 55)

\section{El terrorismo y bioterrorismo ante la supervivencia humana}

Van Rensselaer Potter (1970), en su artículo, "Bioethics, The science of survival”, escribió:

La humanidad tiene la necesidad urgente de una nueva sabiduría que provea el "conocimiento de cómo usar el conocimiento" para la 
supervivencia del hombre [...] Este concepto de la sabiduría como una guía para la acción - el conocimiento de cómo usar este conocimiento para un bien social- podría ser llamado "la ciencia de la supervivencia. (p. 127)

Un año después, en su libro, Bioethics, Bridge to the Future, lo adoptaría como el primer capítulo de su obra (Potter, 1971, p. 25).

Volviendo a la publicación de 1970, Potter escribe: "las decisiones políticas hechas bajo la ignorancia del conocimiento biológico, o retándolo, pueden poner en peligro el futuro del hombre y ciertamente el futuro de los recursos biológicos de la tierra para las necesidades humanas" (p. 130). Este texto responde al mundo actual en el que se intensifican y multiplican los riesgos biológicos que ponen en peligro la seguridad humana, los medios de vida, la salud individual y colectiva, incluso, la supervivencia de humanos, ganados y cultivos como consecuencia de los procesos de globalización y mundialización que, como lo señalan Mercado y Cedillo (2006), colocan "al alcance de muchos sectores y regiones del orbe [los progresos científicos y tecnológicos de los cuales] también son beneficiados los grupos terroristas" (p. 240), asunto de extrema importancia, teniendo en cuenta "que el bioterrorismo tiene una base biotecnológica importante" (Mayorga, 2006, p. 65).

Del reto al conocimiento biológico, de cómo se benefician los grupos terroristas de los progresos científicos y tecnológicos, dan cuenta, tras "los ataques del 11 de septiembre, las amenazas bioterroristas del ántrax [que] pusieron de manifiesto la vulnerabilidad trasnacional tanto de los países ricos como pobres” (Fernández-Pereira, 2005, p. 69) y explican nuestro interés en entrelazar bioética, bioterrorismo y supervivencia humana en el marco del bioderecho y la seguridad nacional, habida cuenta del impacto que este flagelo puede presentar dentro del Estado colombiano. 


\section{Reflexión bioética en el marco del bioderecho aplicable al bioterrorismo}

Reflexionar desde la bioética en el marco del bioderecho en lo atinente al bioterrorismo lleva a adentrarnos en la llamada guerra biológica que debe ser examinada prima facie, teniendo en cuenta lo que demarca la historia contemporánea en cuanto a la rendición, incapacitación o destrucción del enemigo mediante el uso de agentes biológicos capaces de infligir daño, producidos por motivaciones políticas, ideológicas, religiosas y étnicas, cuyo propósito es generar terror en las poblaciones y trastornar la gestión de los regímenes establecidos conforme a la organización y funcionamiento de los Estados. Se ha dicho que, en la literatura jurídica, el bioterrorismo no se ha definido ampliamente, cuya expresión adolece de conceptualización epistemológica en la Real Academia de la Lengua Española (RAE). Sin embargo, es menester señalar la aproximación que desde la doctrina realiza el jurista José Luis de la Cuesta (2011):

El bioterrorismo constituye una modalidad de terrorismo que suele identificarse con el uso (o amenaza de uso) criminal de gérmenes o agentes biológicos - microorganismos patógenos (bacterias, hongos, virus), toxinas y toda suerte de material biológico-, susceptibles de causar enfermedades y muerte (no sólo en las personas, sino también, como en el "agro terrorismo", en los animales o plantas), por lo general, a través de su introducción en los elementos naturales o en los suministros alimentarios. Estos agentes, en principio naturales, son susceptibles de manipulación y modificación para aumentar su capacidad de penetración, sus potencialidades patógenas o letales y su resistencia; hay quien señala incluso que, dados los avances de la Ingeniería genética, es posible su clonación selectiva, de modo que centren su ataque en determinadas etnias o razas, especialmente predispuestas a ciertas enfermedades, lo que les convertiría en un modo especialmente eficaz de comisión del crimen de genocidio. (p. 298)

Via Inveniendi Et Iudicandi

e-ISSN: 1909-0528 | DOI: https://doi.org/10.15332/19090528

Vol. 16 N.o 2 | julio-diciembre del 2021 
A partir del análisis que, de la conducta del ser humano, en los ámbitos de la biología, las biociencias y la biotecnología, hace la bioética, a través del discurso dialógico de esta como ciencia de la supervivencia humana, la guerra a todas luces es una actividad de anti supervivencia. Por ende, desde el punto de vista bioético no es aceptable, teniendo en cuenta que las armas biológicas producidas con virus, hongos y bacterias vivas o con toxinas producidas por ellos son moralmente cuestionables, bajo el entendido de que las armas biológicas son una amenaza para la vida humana (Anaya-Velázquez, 2002).

Entendida la bioética como ética de la vida que estudia los problemas morales, surge la obligación moral común a la luz de los derechos humanos por parte de los individuos mediada por valores emergentes, principios e ideales éticos y bioéticos como el non nocere (principio de no maleficencia o no hacer daño) establecidos en el marco de un discurso bioético amplio con la finalidad que se erija como una norma universal en la humanidad independientemente de la cultura, el origen étnico, la orientación política o la religión para que bajo ninguna circunstancia se desarrollen, produzcan, almacenen o adquieran agentes microbianos $\mathrm{u}$ otros agentes biológicos o toxinas de cualquier origen y método de producción, como armas para atentar contra el semejante y su dignidad como persona, tal como se establece por parte de la Organización de las Naciones Unidas (NU), en la Convención sobre Armas Biológicas y Tóxicas de 1972 (Convención NU, 10 de abril de 1972); y la especial protección que ofrece la Declaración Universal sobre el Genoma Humano y los Derechos Humanos (1997), en el sentido del reconocimiento de los derechos humanos, libertades fundamentales y la dignidad de las personas en acopio de la no discriminación fundamentada en las características genéticas (UNESCO, 1997). 
De la misma manera lo establece la Declaración Universal de Bioética y Derecho Humanos (2005), al señalar que los intereses y el bienestar de la persona deberían tener prioridad con respecto al interés exclusivo de la ciencia o la sociedad, en este caso, aplicado a aquellos intereses sociales, políticos y económicos por los cuales se perpetran actos de bioterrorismos encaminados a generar intimidación y coerción mediante armas biológicas.

Ahora bien, el bioterrorismo, que se ha entendido como una nueva forma de terrorismo, es una de las mayores preocupaciones de la sociedad, de los gobiernos y de la comunidad científica, cuyas amenazas se aplican también a cuestiones ideológicas o creencias culturales. De esta manera, las toxinas biológicas o microorganismos se utilizan como armas biológicas, siendo herramientas de amenaza y violencia contra los seres humanos, así como para el ambiente. Es así como, en 1995, en Japón se utilizó el gas para llevar a cabo un ataque terrorista en el tren subterráneo de Tokio. La organización que planeó el ataque bioterrorista empleó esporas de carbunco y toxina botulínica, además de haber obtenido muestras del virus del Ébola para propagarlo más tarde.

Así mismo, en Dallas, estado de Oregón, en 1984, los miembros de un culto planearon enfermar los vecinos del condado el día de las elecciones. Para ello, contaminaron con la bacteria Salmonella Typhimurium las barras de ensaladas en 10 restaurantes, provocando una epidemia de salmonelosis (Anaya-Velázquez, 2002). Estos hechos demuestran la posibilidad de producir daño con agentes biológicos si no existen medidas éticas y legales que lo impidan.

El 2001, la Organización Panamericana de la Salud (OPS) planteó el uso intencional de agentes biológicos y químicos a raíz de los actos terroristas del 11 de septiembre en Estados Unidos, generando la inquietud sobre posibles ataques bioterroristas, teniendo en cuenta el descubrimiento de 
varios casos de carbunco (ántrax) y los intentos de propagar la bacteria por correo, que permitieron mostrar la realidad de la amenaza con agentes químicos y biológicos. Se señala igualmente que los adelantos de la biotecnología aumentan la inquietud por el bioterrorismo ante la posibilidad del uso inadecuado de la investigación genética para el desarrollo de armas biológicas más potentes y la propagación de nuevas enfermedades infecciosas (OPS, 2001).

De manera complementaria, en el documento "Terrorismo biológico y químico: plan estratégico de preparación y respuesta. Recomendaciones del grupo de trabajo de planificación estratégica de los CDC" (2020), el catedrático español de derecho penal, José Luis de la Cuesta (2011), establece lo planteado por la Organización Panamericana de la Salud/Organización Mundial de la Salud), respecto a la clasificación de los agentes biológicos en tres categorías:

1) Categoría A: Microorganismos susceptibles de generar riesgo para la seguridad nacional, por su facilidad de diseminación o transmisión de persona a persona, potenciales tasas de mortalidad elevada y de grave ataque a la salud pública, y susceptibilidad de provocación de pánico en la colectividad e importantes trastornos sociales, requiriendo, por ello, medidas especiales de preparación y prevención desde el prisma de la salud pública. Se incluyeron aquí el Carbunco, el Botulismo, la Peste, la Viruela mayor, la Tularemia y las Fiebres hemorrágicas víricas.

2) Categoría B: Agentes de propagación moderadamente sencilla, con morbilidad no elevada y baja mortalidad, pero que exigen mejorar la capacidad de diagnóstico, seguimiento y vigilancia de las enfermedades: Brucelosis, Toxina épsilon de clostridium perfringens, ciertas amenazas para la inocuidad de los alimentos, Muermo, Melioidosis, Psitacosis, Fiebre Q, Toxina ricínica de Ricinus communis, Enterotoxina estafilocócica B, Tifus exantemático, Encefalitis vírica y amenazas para la inocuidad del agua.

Via Inveniendi Et Iudicandi

e-ISSN: 1909-0528 | DOI: https://doi.org/10.15332/19090528

Vol. 16 N.o 2 | julio-diciembre del 2021 
3) Categoría C: Agentes patógenos emergentes, susceptibles de modificación genética con objeto de su propagación masiva, fáciles de producir y propagar, y de posible morbilidad y mortalidad altas, así como importante incidencia sobre la salud. Ejemplos: el virus de Nipah y los hantavirus. (p. 298)

En relación con el bioderecho internacional existen dos convenciones internacionales sobre el bioterrorismo. En primer lugar, la Convención sobre la prohibición del desarrollo, la producción y el almacenamiento de armas bacteriológicas (biológicas) y toxínicas, y sobre su destrucción (1972) precitada es una norma mundial contra las armas biológicas. Habida cuenta que en su preámbulo está señalado que el empleo de las armas biológicas repugna a la conciencia de la humanidad. Es así como esta Convención prohíbe los agentes biológicos o toxinas perjudiciales, no solo para los seres humanos, sino también para los animales y las plantas (Feakes, 2018). En segunda instancia, la Convención sobre la Prohibición de la Producción, Desarrollo, Almacenamiento y Uso de las Armas Químicas y su Destrucción (1997) define las armas químicas en dos grandes aspectos:

a) Las sustancias químicas tóxicas o sus precursores, salvo cuando se destinen a fines no prohibidos por la presente Convención, siempre que los tipos y cantidades de que se trate sean compatibles con esos fines;

b) Las municiones o dispositivos destinados de modo expreso a causar la muerte o lesiones mediante las propiedades tóxicas de las sustancias especificadas en el apartado a) que libere el empleo de esas municiones o dispositivos. (p. 3)

A su vez, define "sustancia química tóxica” como

Toda sustancia química que por su acción química sobre los procesos virtuales pueda causar la muerte, la incapacidad temporal o lesiones

Via Inveniendi Et Iudicandi

e-ISSN: 1909-0528 | DOI: https://doi.org/10.15332/19090528

Vol. 16 N.० 2 | julio-diciembre del 2021 
permanentes a seres humanos o animales. Quedan incluidas todas las sustancias químicas de esa clase, cualquiera que sea su origen o método de producción y ya sea que se produzcan en instalaciones, como municiones o de otro modo. (p. 3)

Por precursor de arma química se entiende:

Cualquier reactivo químico que intervenga en cualquier fase de la producción por cualquier método de una sustancia química tóxica. Queda incluido cualquier componente clave de un sistema químico binario o de multicomponentes. (p. 3)

Esta convención se ha constituido como la normatividad internacional de mayor interés dentro del ámbito del bioterrorismo que presenta mayor relevancia en lo que respecta a las armas de destrucción masiva de carácter químico y biológico (Dasilva, 1999).

Teniendo en cuenta la situación fáctica de riesgo que representa el bioterrorismo, existen falencias a nivel de los Estados, como lo es el caso de Colombia, en el sentido de incorporar en su ordenamiento jurídico la adopción de normatividad eficaz que incorpore el bioterrorismo como una amenaza al Estado social de derechos en cuanto a la vida y el viviente en todas sus manifestaciones para desarrollar el artículo 81 de la Constitución Política de Colombia, que a la letra dice:

Artículo 81. Queda prohibida la fabricación, importación, posesión y uso de armas químicas, biológicas y nucleares, así como la introducción al territorio nacional de residuos nucleares y desechos tóxicos.

El Estado regulará el ingreso al país y la salida de él de los recursos genéticos, y su utilización, de acuerdo con el interés nacional.

Asimismo, se hará necesario definir jurídicamente el bioterrorismo acompañado de las políticas que aseguren la prevención y control de 
armas biológicas que atenten contra la dignidad humana en el territorio de Colombia y contribuir al fomento de la investigación biológica que permita detectar la presencia de microorganismos en el medio ambiente como consecuencia de ataques bioterroristas. De igual manera, desde la educación formar al personal de salud y de defensa con el propósito de detectar y manejar agentes biológicos. Por tanto, la bioética debe constituirse como un ojo avizor desde el principio de no maleficencia, responsabilidad y precaución como un imperativo moral con el propósito de promover la supervivencia humana. Asimismo, el Consejo Nacional de Bioética debe empoderarse de los usos éticos de los avances en genética y la investigación biotecnológica, con el propósito de propender por la seguridad nacional en la lucha contra el bioterrorismo desde la mirada bioética, como órgano consultor del gobierno colombiano acorde con las Declaraciones Universales de la UNESCO, priorizando la Declaración Universal de Bioética y Derechos Humanos de 2005 para la seguridad y protección del pueblo colombiano, especialmente en las investigaciones que involucran a los sujetos humanos. Habida consideración, que los ataques bioterroristas podrían presentarse desde el silencio de los laboratorios y generar problemas éticos y bioéticos como lo plantea Eric Meslin (2002):

Ya no será suficiente centrar la atención bioética únicamente en si la "ética" de un ensayo clínico es tan buena como la "ciencia" (una justificación importante para la investigación farmacéutica y biotecnológica). La amenaza del bioterrorismo requiere que se preste mayor atención a las consideraciones económicas, políticas y éticas. (p. 1)

A este respecto, el debate atinente al bioterrorismo desde el entramado existente entre la bioética y el bioderecho apenas comienza ante los avatares de la ciencia y la biotecnología que compromete significativamente la vida humana y del ecosistema. 


\section{Impacto del bioterrorismo para la seguridad nacional}

El bioterrorismo, en su condición de amenaza para la estabilidad de los

Estados, afecta la seguridad nacional y por su conducto a la salud pública. Camus (1979): "Sé únicamente que hay en este mundo plagas y víctimas y que hay que negarse tanto como le sea a uno posible a estar con las plagas" (p. 174); condición que hace necesario realizar su análisis desde la biopolítica y el bioderecho.

La Constitución Política de Colombia (1991), título I, artículo 2, respecto a los fines esenciales del Estado:

Servir a la comunidad, promover la prosperidad general y garantizar la efectividad de los principios, derechos y deberes consagrados en la Constitución [...] defender la independencia nacional, mantener la integridad territorial y asegurar la convivencia pacífica y un orden justo.

La seguridad nacional, se define como "La situación en la cual los intereses de la Nación se hallan a cubierto de interferencias y perturbaciones substanciales” (Fuerzas Militares de Colombia, 1996, p. 21). Se consideran interferencias y perturbaciones substanciales: "i) conflictos de estructura, ii) conflictos ideológicos, iii) conflictos por intereses personales o de grupos y iv) conflictos entre Estados" (p. 23); siendo potenciales amenazas el terrorismo y su consecuente transición al bioterrorismo.

En relación con el uso de armas biológicas, Kottow (2003): "El desarrollo de armas biológicas siempre fue motivo de controversia, por lo que se intentó justificarlas moralmente como medios efectivos de represalia y disuasión, estrictamente reservados para fines defensivos [...] también como represalia o como arma ofensiva" (p. 299).

Haciendo un paralelo entre los conceptos de bioterrorismo y terrorismo de Estado, en el marco de la biopolítica, Roberto Esposito (2006) comparte un hecho de amplio renombre en la historia de las decisiones 
políticas modernas al interior del gobierno ruso, bajo la conducción de Vladimir Putin:

Rusia, 23 de octubre de 2002. Grupos especiales de la policía del Estado irrumpen en el Teatro Dubrovka de Moscú, donde un comando checheno tiene como rehenes a casi mil personas, y provocan, con un gas paralizante de efectos letales, la muerte de 128 rehenes y de casi todos los terroristas. El episodio, justificado e incluso tomado como modelo de firmeza por otros gobiernos, marca un paso más en la dirección antes comentada. (Esposito, 2006, p. 11)

En flagrante vulneración a los derechos humanos, el derecho internacional humanitario y el derecho internacional de los conflictos armados, algunos Estados han acudido al uso del bioterrorismo con el propósito de "mantener su autonomía, supervivencia y la búsqueda de sus objetivos e intereses"; aun siendo considerados actos inhumanos (Rincón y Peñas, 2015). Es el caso del empleo del poder militar sirio por parte del régimen de Bashar al-Ásad en el 2013, siendo fuertemente cuestionado por la comunidad internacional en cabeza de las NU, respecto al lamentable uso de armas de destrucción masiva en contra de la nación siria, lo cual generó una seria afectación a la seguridad nacional.

Cerrando el abordaje del pensamiento foucaultiano, y de cara a los Estados nacionales y posnacionales, Ilivitzky (2011), en su obra, Habermas y la constelación posnacional, comparte su postura sobre la teoría de la política internacional ante la posguerra fría, de cara al contraste de algunos sucesos ocurridos a lo largo de la historia moderna:

Luego de la caída de la Unión Soviética en 1991 y del consiguiente término del conflicto que dividió a gran parte de los Estados nacionales del globo - la Guerra Fría- muchas voces se alzaron, quizás precipitadamente, tanto para sostener que la historia habría llegado a su fin, de acuerdo con una tesis propuesta por Hegel y Kojève retomada

Via Inveniendi Et Iudicandi e-ISSN: 1909-0528 | DOI: https://doi.org/10.15332/19090528 Vol. 16 N.० 2 | julio-diciembre del 2021 
luego por Francis Fukuyama (1992), como para afirmar que el próximo enfrentamiento relevante se sustentaría ya no en patrones ideológicogeopolíticos sino más bien en características idiosincrático culturales, de acuerdo con la postura sostenida por Samuel Huntington (1997) en El choque de civilizaciones. (IIivitzky, 2011, pp. 39-40)

Respecto a la promoción de la "seguridad humana" y su relación con los derechos fundamentales, en el marco de la supervivencia, y la "vulnerabilidad" como principio emergente de la bioética; las NU, a través de la Oficina de Coordinación de Asuntos Humanitarios (2012, p. 5), establece:

La seguridad humana se ocupa de la amplia gama de condiciones en las cuales la supervivencia, los medios de subsistencia y la dignidad de las personas, en particular de las más vulnerables, se ven gravemente amenazadas. Un factor indispensable para la seguridad humana es la promoción de sistemas políticos, sociales, económicos, ambientales, militares y culturales que, juntos, proporcionen a las personas los elementos básicos para alcanzar la paz, el desarrollo y el progreso humanos. (A.G. NU, 2012, A/RES/66/290).

Enlazando los conceptos de "subjetividad, libertad, justicia, poder y biopolítica" de cara a la seguridad nacional, permite que Acosta (2016), en su obra, Poder y subjetividad en Michel Foucault: traslaciones, modificaciones, ambivalencias, presente el planteamiento del filósofo francés, que permite tajantemente ampliar las posibilidades de análisis ante la temática que nos ocupa, en el entendido que el Estado debe garantizar la convivencia, la seguridad y la supervivencia de la nación, blindándola de amenazas, ante las cuales sea considerada como vulnerable:

De hecho, en Vigilar y castigar ya se vislumbra el incipiente procedimiento regulador del que se valdrá la biopolítica a la hora de 
ejercer el poder mediante el mecanismo del examen. Efectivamente, este no solo permite tratar al individuo como exhaustivamente analizable, sino que también permite el conocimiento exhaustivo de otros individuos mediante la comparación entre los mismos y con ello, conocer su posición en la población. (Acosta, 2016, p. 27)

Es de anotar que del terrorismo ha dado un paso a una modalidad que refiere al bioterrorismo, como se ha explicitado en este artículo de reflexión, habida cuenta de la necesidad de blindar los intereses de los Estados ante las amenazas, interferencias y perturbaciones que se suscitan por conflictos de estructura, ideológicos y de la hegemonía de los Estados como mecanismos de poder. Para nuestro ordenamiento jurídico es pertinente fortalecer y desarrollar en consideración a lo consagrado en la Carta Política colombiana, normatizar lo atinente al uso de armas biológicas con el propósito de blindar los intereses de la nación en la preservación de la vida y del viviente en todas sus modalidades, tal como lo expresa la prohibición que contempla el artículo 81 de la Constitución Política de Colombia, que requiere de una urgente regulación ante los avances de las ciencias y biotecnologías, que si bien generan beneficios para la humanidad, en otras manos producen maleficencia con afectaciones a la vida, llegando a constituirse como delitos de lesa humanidad y de carácter ambiental, cuyas falencias manifiestas tienen, en la actualidad, las leyes de la República de Colombia (Zárate-Cuello, 2019).

\section{Conclusiones}

El paso del terrorismo al bioterrorismo se explica por el denominado atractivo por las armas biológicas derivado del fácil acceso a los agentes biológicos (organismos vivos o sustancias patógenas) que, al ser liberados, pueden llegar a dañar, someter a riesgos y amenazar la supervivencia en su sentido global; es decir, afectación de todo lo viviente, al igual que las 
armas nucleares: humanos, ganados y cultivos. Entonces, cabe preguntar: ¿por qué las razones para este atractivo por las armas biológicas?

Una primera respuesta podría ser: porque esta modalidad de infligir daño a lo viviente puede realizarse desde el silencio de los laboratorios; una segunda, por su potencialidad de ser varios cientos de veces más letales que las químicas y nucleares, una tercera, por su relativa indetectabilidad por los sistemas de seguridad rutinarios, el alcance de los grupos interesados en cualquier parte de la naturaleza, su fácil transporte y el bajo costo en su producción-generación.

Algunas de las razones para este paso, aquí expuestas, demuestran que el bioterrorismo está latente, intensifica y multiplica los riesgos biológicos, pone de manifiesto la vulnerabilidad mayor de la población civil con respecto a la militar y revelan la necesidad de una reflexión bioética con los dilemas y problemas que presenta para la ética de la vida en el marco del bioderecho y la seguridad nacional, con el fin de hacer frente a este tipo de amenazas, cuya reflexión bioética desde el primun non nocere, como principio de no maleficencia o no hacer daño, el cual enciende las alarmas del bioderecho frente a los impactos de las amenazas bioterroristas que se nutren desde los avances de las ciencias y biotecnologías con el imperativo de poder; de lo que deviene la afectación manifiesta en la supervivencia humana y del ecosistema.

En suma, de acuerdo con lo dilucidado en el presente artículo, el bioterrorismo es un asunto pendiente en la agenda del Legislador, en el sentido de incorporar en el ordenamiento jurídico desde la definición y las situaciones de impacto del bioterrorismo en el Estado colombiano, como un asunto de seguridad nacional, seguridad humana y seguridad ambiental, desde el diálogo de saberes inter y transdisciplinares de la bioética, en el marco del bioderecho interno, iel debate apenas comienza! 


\section{Referencias}

Acosta, L. (2016). Poder y subjetividad en Michel Foucault: traslaciones, modificaciones, ambivalencias. Oxímora: revista internacional d'Ètica i Política, [en línea], 2016, $n .^{o} 8$, 20-35. https://raco.cat/index.php/Oximora/article/view/310063

Al Kaabi, J. (2017). La gestion de la menace terroriste. Le système français de prévention et de répression [tesis doctoral]. Université Jean Moulin. https://scdresnum.univ-lyon3.fr/out/theses/2017 out alkaabi j.pdf

Anaya-Velázquez, F. (2002). Bioética, armas biológicas y los microbiólogos.

Microbiología, 44(1), 38-45.

Aron, R. (1962). Paix et Guerre entre les nations ( $3 \cdot^{a}$ ed.). Calmann-Lévy.

Camus, A. (1979). La peste. Sudamericana.

http://resistir.info/livros/camus la peste castelhano.pdf

Centers for Disease Control and Prevention, United States Department of Health and Human Services (2014). Resumen del ántrax. Guía básica para comprender el ántrax. https://www.cdc.gov/anthrax/es/images/Anthrax-book-spanish-updatefinal-highres.pdf

Clauzon, L. (2009). Guerre Biologique et Bioterrorisme ou comment la nature devient une arme [tesis doctoral]. Université Lorraine. http://docnum.univlorraine.fr/public/SCDPHA T 2009 CLAUZON LORENE.pdf

Constitución Política de Colombia [C.P.]. Art. 2, título I. Julio 7 de 1991 (Colom.).

Culp, R. B. (2019). Expert Perspectives on How the Islamic State Potentially Shaped the Future of Islamic Transnational Terrorism: An Exploratory Study [tesis doctoral]. Minneapolis: Walden University. https://scholarworks.waldenu.edu/cgi/viewcontent.cgi?article $=8164 \&$ context $=$ diss ertations

Dasilva, E. (1999). Biological warfare, bioterrorism, biodefence and de bilogical and toxin weapon convention. Electronic Journal of Biotechnology, 2(3), 99-129. https://doi.org/10.2225/vol2-issue3-fulltext-2

De la Cuesta, J. (2011). Bioterrorismo (jurídico). Enciclopedia de bioderecho y bioética.

En C. M. Casabona (dir.), Cátedra Interuniversitaria de Derecho y Genoma Humano (t. I). https://enciclopedia-bioderecho.com/voces/51

Via Inveniendi Et Iudicandi

e-ISSN: 1909-0528 | DOI: https://doi.org/10.15332/19090528

Vol. 16 N.o 2 | julio-diciembre del 2021 
Esposito, R. (2006). Bíos, biopolítica y filosofía. Amorrortu.

Feakes, D. (2018). La Convención sobre las Armas Biológicas y su aplicación práctica. Boletín. Organización Mundial de Sanidad Animal-OIE.

Fernández-Pereira, J. P. (2005). Seguridad humana [tesis doctoral]. Universidad Autónoma de Barcelona.

https://www.iidh.ed.cr/multic/UserFiles/Biblioteca/IIDHSeguridad/12 2010/d54 of1cb-719b-4b49-95b1-f61a7faa7ab2.pdf

Franco-Paredes, C. y Rodríguez Morales, A. J. (2004). Bioterrorismo: preparándose para lo impensable. CIMEL, 9(1), 31-40. http://www.scielo.org.mx/pdf//ric/v57n5/v57n5a7.pdf

Fuerzas Militares de Colombia. (1996). Manual de seguridad y defensa nacional (MANUAL FF.MM. 3-43. Reservado). Imprenta y Publicaciones de las Fuerzas Militares de Colombia.

Gayraud, J. F. y Senat, D. (2002). Le terrorisme. PUF.

Gómez-Pineda F. H. (2014). ¿Qué es la bioética? De vuelta a la división de la vida humana en vida/bíos y vida/zoé. Universidad Libre, sede Cali. https://repository.unilibre.edu.co/bitstream/handle/10901/17867/2014\%20-\%20 Qu\%C3\%A9\%2oes\%2ola\%20Bio\%C3\%A9tica\%20-\%20Floro\%20Hermes\%20G\%C 3\%B3mez\%20Pineda.pdf? sequence=1\&isAllowed $=\mathrm{y}$

González, J. L. y Fernández, A. (2008). Sobre el concepto jurídico penal de terrorismo. Teoría y Derecho: Revista de Pensamiento Jurídico, (3), 34-58.

Huertas, O., López, D. y Jerez Avilán, L. S. (2019). La “paz” como escenario de disputa ideológica. Revista IUSTA, 1(50), 19-38. https://revistas.usantotomas.edu.co/index.php/iusta/article/view/4885/html

IIivitzky, M. (2011). Habermas y la constelación posnacional. https://dialnet.unirioja.es/servlet/autor? codigo $=3033627$

Kottow, M. (2003). Bioterrorismo, biodefensa, bioética. Cad. Saúde Pública, 19(1), 297-303. https://www.scielo.br/pdf/csp/v19n1/14931.pdf

Kottow, M. H. (2004). Vulnerability: what kind of principle is it? Med Health Care Philos., 7(3), 281-287.

Via Inveniendi Et Iudicandi

e-ISSN: 1909-0528 | DOI: https://doi.org/10.15332/19090528

Vol. 16 N.o 2 | julio-diciembre del 2021 
Kottow, M. (2007). Ética de protección: una propuesta de protección bioética. Universidad Nacional de Colombia.

Kottow, M. (2012). Vulnerabilidad entre derechos humanos y bioética. Relaciones tormentosas, conflictos insolutos. Derecho PUCP, (69): 25-44.

Kruglanski, A. W. y Fishman, S. (2009). Psychological Factors in Terrorism and Counterterrorism: Individual, Group, and Organizational Levels of Analysis. Social Issues and Policy Review, 3(1), 1-44.

Lang, P. (2003). Rapport d'information déposé en application de l'article $145 d u$ Règlement par la Commission de la Défense Nationale et des Forces Armées sur le bioterrorisme. Assemblée Nationale.

Laqueur, W. (1979). Le terrorisme. Presses Universitaires.

Laqueur, W. (2003). La guerra sin fin. El terrorismo en el siglo XXI. Destino.

Manacorda, S. (2013). Les conceptions de l'Union européenne en matière de terrorisme. En H. Laurens y M. Delmas-Marty (dir.). Terrorismes-Histoire et droit. CNRS Éditions.

Matamoros-Martínez, R. (2004). El marco jurídico del bioterrorismo. Anuario Jurídico y Económico Escurialense, n. ${ }^{\circ}$ XXXVII, 17-46.

Mayorga, L. (2006). Las células y sus moléculas. En R. Gotthelf et ál. (dir.), La investigación desde sus protagonistas: senderos y estrategias. Editorial de la Universidad Nacional de Cuyo.

Merari, A. (2002). Du terrorisme comme stratégie d'insurrection. En G. Chaliand (dir.), Les stratégies du terrorisme, nouvelle édition augmentée. Desclée de Brouwer.

Mercado, A. y Cedillo, R. (2006). Mundialización y terrorismo: la sociedad del "riesgo mundial”. Convergencia, 13(42), 217-246.

Meslin, E. (2002). Bioterrorism and bioethics: Challenges for industry, government and society. Journal of Commercial Biotechnology, 9(2), 101-109.

NU. Cuestión de las armas químicas y bacteriológicas (biológicas). 2603 (XXIV), NU. (dic. 16, 1969).

NU. Convención sobre la prohibición del desarrollo, la producción y el almacenamiento de armas bacteriológicas (biológicas) y toxínicas y sobre su destrucción, NU (abr. 10, 1972).

Via Inveniendi Et Iudicandi

e-ISSN: 1909-0528 | DOI: https://doi.org/10.15332/19090528

Vol. 16 N.० 2 | julio-diciembre del 2021 
NU. Declaración Universal sobre el Genoma Humano y los Derechos Humanos. Actas de la Conferencia General. 29. ${ }^{a}$ reunión. Vol. 1, 45-50. NU (oct. 21 a nov. 12, 1997).

NU. Los derechos humanos, el terrorismo y la lucha contra el terrorismo, NU (septiembre, 2008). https://www.ohchr.org/Documents/Publications/Factsheet32sp.pdf

NU. Fondo Fiduciario de las Naciones Unidas para la Seguridad Humana. Dependencia de Seguridad Humana. Oficina de Coordinación de Asuntos Humanitarios. La seguridad humana en las Naciones Unidas, NU (sep. 10, 2012). https://www.unocha.org/sites/dms/HSU/Outreach/1241684 Spanish\%20HUMAN\%2OSECURITY\%20Brochure web December\%2010. pdf

OPS. Uso intencional de agentes biológicos y químicos: riesgos y recomendaciones.

Boletín Epidemiológico, 22(3), 1-3 (septiembre, 2001). http://cidbimena.desastres.hn/docum/ops/publicaciones/Epidemiologico/EB v2 2n3.pdf

Oromí-Durich, J. (2002). Bioterrorismo y contaminación del agua. Med Integral, 40(7), 283-6.

Ponce de León-Rosales, S., Lazcano-Ponce E., Rangel-Frausto M. S., Sosa-Lozano, L. A., Huerta-Jiménez, M. A. (2001). Bioterrorismo: apuntes para una agenda de lo inesperado. Salud Pública Méx., 43(6), 589-603. https://www.researchgate.net/publication/26376247 Bioterrorismo apuntes par a una agenda de lo inesperado

Pereira-Hernández, C. (2007). Bioterrorismo. Boletín de información, (298), 49-72.

Potter, V. R. (1970). Bioethics, the Science of Survival. Perspectives in Biology and Medicine, 14(1), 127-153.

Potter, V. R. (1971). Bioethics, Bridge to the Future. Prentice Hall.

Ramírez-Gil, L. F. (2014). Bioética y terrorismo: una mirada inaplazable. Revista Colombiana de Bioética, 9(2), 63-72.

Rincón, K. y Peñas, A. (2015). El delito político en Colombia frente al derecho internacional humanitario. Revista IUSTA (43), 67-90. https://www.redalyc.org/pdf/5603/560358705005.pdf

Via Inveniendi Et Iudicandi

e-ISSN: 1909-0528 | DOI: https://doi.org/10.15332/19090528

Vol. 16 N.o 2 | julio-diciembre del 2021 
Sánchez Medero, G. (2018). Amenazas pasadas presentes y futuras: las guerras asimétricas / Gema Sánchez Medero [y otros cuatro autores]. Bucaramanga (Colombia). Universidad Santo Tomás.

http://publicaciones.ustabuca.edu.co/images/Documentos\%20Publicaciones/selec cion/Amenazas pasadas presentes y futuras.pdf

Santa Rita Tamés, G. (2012). El delito de organización terrorista: un modelo de derecho penal del enemigo [tesis doctoral]. Universidad de Sevilla.

https://idus.us.es/bitstream/handle/11441/71110/Tesis_Santa\%20Rita\%20Tames. pdf? sequence $=1$ \&isAllowed $=\mathrm{y}$

Soberanis, O. y Ramos, C. (2009). El bioterrorismo desde el punto de vista de la salud pública. Enf Inf Microbiol, 29(1), 29-36.

Sommier, I. (2000). Le terrorisme. Flammarion.

U.S. General Accounting Office (2001). Bioterrorism. Review of Public Health Preparedness Programs.

UNODC. Módulo 2. Marco jurídico universal contra el terrorismo. En Plan de estudios para la capacitación jurídica contra el terrorismo. NU (octubre, 2018). https://www.unodc.org/documents/terrorism/Publications/Module\%202/Module 2 Spanish.pdf

Zárate-Cuello, A. (2019). Núcleo problémico II. Problemas emergentes de la Bioética. Seminario Doctorado en Bioética. Normatividad en biomedicina, biotecnología y eugenesia. Legislación comparada entre España y Colombia. Eugenesia positiva, estudio de casos. Universidad Militar Nueva Granada.

Via Inveniendi Et Iudicandi

e-ISSN: 1909-0528 | DOI: https://doi.org/10.15332/19090528

Vol. 16 N.० 2 | julio-diciembre del 2021 